Int. J. Electrochem. Sci., 14 (2019) 7495 - 7506

\title{
Direct Electrochemistry of Glucose Oxidase on a Graphene- Graphene Oxide Nanocomposite-Modified Electrode for a Glucose Biosensor
}

\author{
Bo Wang ${ }^{1}$, Xiaoli Wang ${ }^{2}$, Zhifang He ${ }^{1}$, Xiufeng Zhao ${ }^{2}$, Linyu Wang ${ }^{1}$ \\ ${ }^{1}$ Hebei Key Laboratory of Heterocyclic Compounds. School of chemical engineering \& materials, \\ Handan University, Handan, 056005, PR China. \\ ${ }^{2}$ Department of medicine, First Hospital of Handan City, Handan, 056005, PR China. \\ *E-mail: hdxyxb@hdc.edu.cn
}

doi: $10.20964 / 2019.08 .34$

Received: 5 April 2019 / Accepted: 20 May 2019 / Published: 30 June 2019

Direct electrochemistry of glucose oxidase (GOD) was conducted on the surface of a novel graphenegraphene oxide (GR-GO) nanocomposite. GR-GO possesses the virtues of excellent biocompatibility and conductivity, and high sensitivity to local perturbations, and can provide a biocompatible microenvironment for protein immobilization and a suitable electron transfer distance between the electroactive centers of GOD and the electrode surface. The voltammetric results indicated that GOD assembled on GR-GO retained its native structure and bioactivity, exhibited a surface-confined process, and underwent an effective direct electron transfer (DET) reaction with an apparent rate constant $\left(\mathrm{k}_{\mathrm{s}}\right)$ of $3.5 \mathrm{~s} \mathrm{~s}^{-1}$. Furthermore, the proposed biosensor exhibited a wider linear response to glucose concentrations between $0.1 \mathrm{mM}$ and $11 \mathrm{mM}$, with a detection limit of $20 \mu \mathrm{M}$ and a much higher sensitivity $\left(15.85 \mu \mathrm{A} \mathrm{mM} \mathrm{m}^{-1} \mathrm{~cm}^{-2}\right)$.

Keywords: direct electron transfer, graphene, graphene oxide, glucose oxidase

\section{FULL TEXT}

(C) 2019 The Authors. Published by ESG (www.electrochemsci.org). This article is an open access article distributed under the terms and conditions of the Creative Commons Attribution license (http://creativecommons.org/licenses/by/4.0/). 